\title{
Relevant Applications of Tools in UG NX CAM Module
}

\author{
En Guang ZHANG ${ }^{1, a}$, Li WANG ${ }^{1}$ \\ ${ }^{1}$ Zhuhai College of Jilin University, 519041 Zhuhai, China
}

\begin{abstract}
In this paper, the methods to establish the custom magazine have been proposed while the UG NX CAM module is employed to conduct the CNC milling programming. At the same time, how to set the parameters of the cutting tool has been also analyzed; in the creation of tools, the use of shank and holder as well as the use of handle check functions in NC machining has been introduced; meanwhile, the secondary rough machining of corner and the application of clean-cut features have been discussed.
\end{abstract}

\section{Introduction}

In recent years, the $\mathrm{CNC}$ machining technology has been greatly developed, which promotes the basic research on $\mathrm{CNC}$ tool materials and the development of new product[1]. The multifunctional complex tools and the modern efficient tools are the mainstream of tool development. The increasing development, the great changes of toll materials and the rapid development of coating technology have greatly promoted the tool development[2]. Currently, the high-speed cutting, the dry machining, the hard cutting and the composite cutting have become the important direction of development. The different cutting technologies use the different tools. For example, the ultra-fine grain carbide cutting tools have been developed to the nanoscale. At present, the main species have trungsten cobalt, (W,Ti)C-Co Cemented Carbide and WC TiC Tac Co. Other super-hard tool materials include the ceramics, CBN (Cubic Boron Nitride) and polycrystalline diamond, etc.

With the development of $\mathrm{CNC}$ machining technology, the tool types as well as the tool materials have obtained great progress. The types of tools are various. In $\mathrm{CNC}$ machining, the applications of tools have become increasingly important. For example, the magazine, the check functions of tools and the use of reference tools are defined in CAM software.

\section{Creation of custom magazine in UG $\mathrm{NX}$}

\subsection{UG NX software.}

UG NX software is a CAD/CAE/CAM manufacturing information software, which has been widely applied in fields of automobiles, general machine, military industry, aerospace, consumer goods, high-tech products and ship design. At present, the latest version of NX software is NX10. The computer-aided design, the engineering

\footnotetext{
a Corresponding author: teamcenter@163.com
}

analysis and the processing can be completed in the same software through employing the NX software without the format conversion, which can ensure the editable feature of model and greatly improve the secondary modification speed of NC program. Currently, the NX software has a wide range of users in Pearl River Delta and Yangtze River Delta.

\subsection{CAM module of UG NX.}

CAM (Computer Aided Manufacturing) refers to the process in which the computer is employed to control and operate the production equipment. The input information includes the process route and the process contents. The output information refers to the movement curve (cutter location file) and the $\mathrm{CNC}$ programs in the process of tooling.

CAM module of UG NX supports drilling, milling, turning and wire EDM as well as the three-axis and multi-axis milling. For the milling, the common processing methods include CAVITY MILLING, PLANAR MILLING, FACE MILLING, ZLEVEL PROFILE MILLING and FIXED_CONTOUR MILLING. The methods to control the tool path are extremely rich, which can meet the demands of any NC programming. The applicable scope and process of different operation types are shown in Table 1.

Table 1. The applicable scope and process of different operation types [3]

\begin{tabular}{|c|c|c|c|}
\hline \multicolumn{2}{|c|}{ Operation type } & Application & Applicable process \\
\hline \multirow[t]{2}{*}{ Drill } & Drilling & Center hole & \multirow{2}{*}{$\begin{array}{l}\text { Hole rough drilling } \\
\text { or finishing drilling }\end{array}$} \\
\hline & Peck_Drilling & Deep hole & \\
\hline \multirow[t]{2}{*}{$\begin{array}{l}\text { Mill- } \\
\text { Planar }\end{array}$} & Face_Milling & \multirow{2}{*}{$\begin{array}{l}\text { Model with } \\
\text { plane } \\
\text { bottom and } \\
\text { vertical } \\
\text { plane side } \\
\text { wall }\end{array}$} & $\begin{array}{c}\text { Face rough } \\
\text { machining or finish } \\
\text { machining }\end{array}$ \\
\hline & Planar_Mill & & $\begin{array}{l}\text { MILL_ROUGH, } \\
\text { finish machining }\end{array}$ \\
\hline $\begin{array}{l}\text { Mill- } \\
\text { Contour }\end{array}$ & Cavity-Mill & $\begin{array}{c}\text { Arbitrary } \\
\text { shape model }\end{array}$ & $\begin{array}{l}\text { mostly used for } \\
\text { rough machining, } \\
\text { and sometimes for }\end{array}$ \\
\hline
\end{tabular}




\begin{tabular}{|c|c|c|c|}
\hline & & $\begin{array}{c}\text { the "steep"model } \\
\text { of } \\
\text { MILL_SEMI_FINI } \\
\text { SH and finishing } \\
\text { machining }\end{array}$ \\
\cline { 2 - 4 } & $\begin{array}{c}\text { Z } \\
\text { level_Profile_ } \\
\text { Steep }\end{array}$ & $\begin{array}{c}\text { "Steep" } \\
\text { model with } \\
\text { a small } \\
\text { angle } \\
\text { between the } \\
\text { Z axis }\end{array}$ & $\begin{array}{c}\text { MILL_SEMI_FINI } \\
\text { SH、 } \\
\text { MILL_FINISH }\end{array}$ \\
& $\begin{array}{c}\text { Arbitrary } \\
\text { shape model }\end{array}$ & MILL_SEMI_FINI \\
& Sixed- & MILL_FINISH \\
\hline
\end{tabular}

\subsection{Creation of custom magazine in UG NX}

Firstly, it is required to create an arbitrary file and "Manufacturing" module is entered from "Start". The processing environment can select "mill contour" initiation. Then, the processing module of UG is entered.

In "Resource Bar", the "operation navigator" can be found. It is required to select "tool view" and the subsequently created tools can be displayed in this view with the form of list. It is required to choose "creating tools" in "creation process". The subtype selects "Mill" and "OK" is clicked to enter "Milling Tool-5 Parameters" tool dialog box. In this dialog box, the geometry parameters of tools and the tool materials can be entered. And it is necessary to set up and generate the shank and holder. Then, it is needed to select "Export Tool to Library" to import the tools to the corresponding database.

It is required to execute the menu command "tool"---"Edit Machining Data Libraries" and input the parameters according to demands. Then, the cutting parameters of tools can be determined. These cutting parameters can be loaded when using this tool.

\subsection{Use of shank and holder}

When creating the tools, it is required to respectively define Tool, Shank and Holder. The tool is shown in Figure 1.

"Use of shank and holder" option helps avoid collision between handle and the workpiece and choose the cutting tool as short as possible during operation. If you want to use the handle to contain the tool path, please open this option.

"Use of shank and holder" is a common cutting parameter for "high milling", "surface contour milling"(according to the drive mode) and "cavity milling". During the "surface contour milling ", "Use of shank and holder" can be used to complete "Area milling" and "automatic cleaning".

The handle and holder in the tool definition dialog box are defined as a pile of stacked cylinders or tapered cylinders, as shown in figure 1. For the "milling area", "automatic cleaning root driving mode" and "high profile milling driving mode" of "fixed axis surface milling", this handle definition can be used to ensure that the tool path without collision. During this operation, these options must switch to "on" to identify the handle.

In the "surface contour milling" and "high milling", if a collision between handle and the workpiece was detected, the collision region would be saved as "twodimensional workpiece" geometry during the operation. The "two dimensional workpiece" geometry can be displayed by in turn highlighting the operation, holding down the mouse button MB3 and selecting "workpiece - display two-dimensional". The geometry can also be displayed even when the other operation is performed. The geometry can be used as clipping geometry in subsequent operations in order to include cutting movement in the area where the left material with the collision between the handle and workpiece need to be removed.

In the "cavity milling", if the system detects a collision between the handle and the workpiece, the collision area will not be cut. In order to remove the non cutting area, all subsequent cavity milling operations must use the "Layer based IPW" option.

In Figure 2, the system uses the holder shape and the minimum clearance value to ensure the safe distance with geometry. The regions which can cause the collision will be excluded from the cutting area. Therefore, there is no toolpath collision when cutting materials. The materials which need to be removed should be updated after each completed cutting layer. It is required to maximum increase the available cutting area. At the same time, as the upper material has been removed, the handle has greater space at the bottom of workpiece. It must be necessary to use longer tools to cut the excluded (collision) area in subsequent operations.

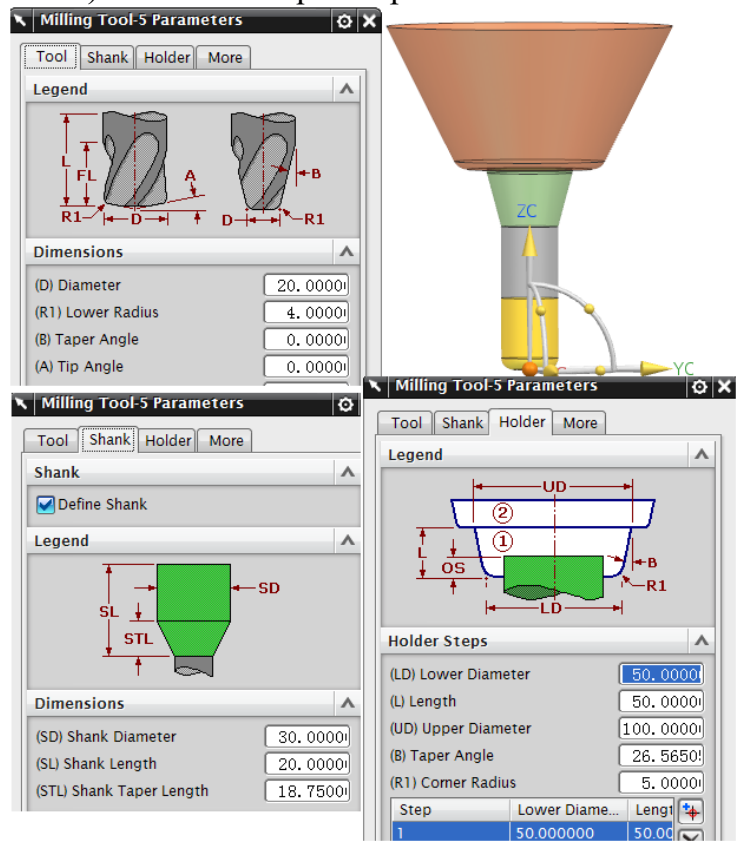

Figure 1. Defining Tool、Shank、Holder 


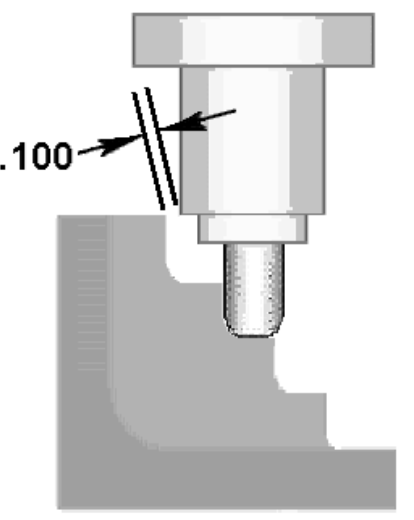

Figure 2. Use of shank detection

\section{Reference tools are used for semi- finishing the corner}

Many of the CAM modules in UG provide a "reference tool" option, such as cavity milling, high milling and fixed axis milling and etc.. Use the reference tool option to eliminate the tool movement in the place where there is no material. When creating a new process, if the using smaller tool refers to the larger one, only the none cutting material with the larger tool will be removed by the smaller one. The reference tool process can be placed before or after the process using the larger tool. It is often to do the rough cutting corners with smaller tool firstly as a process of reference tool before the process of contour milling with larger tool.

When you want to cut the remaining material in the corner missed by the last tool, you can use the "reference tool", as shown in figure 3. The remaining material may be that left over between the wall and the bottom due to the corner radius of the tool, or may be that left between the walls due to the diameter of the tool. This cutting is similar to the other "cavity milling" operations, however, it is limited to the corner area operation. The reference tool is usually used as a tool for rough machining of the area. The system calculates the remaining material for the specified reference tool, and then defines the cutting area for the current operation. Figure 4 shows the cavity milling path using automatic block as a blank. It has no reference tool.

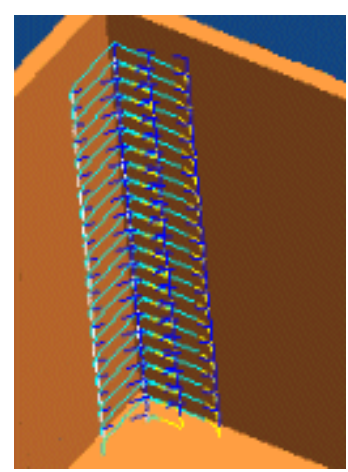

Figure 3. Corner only

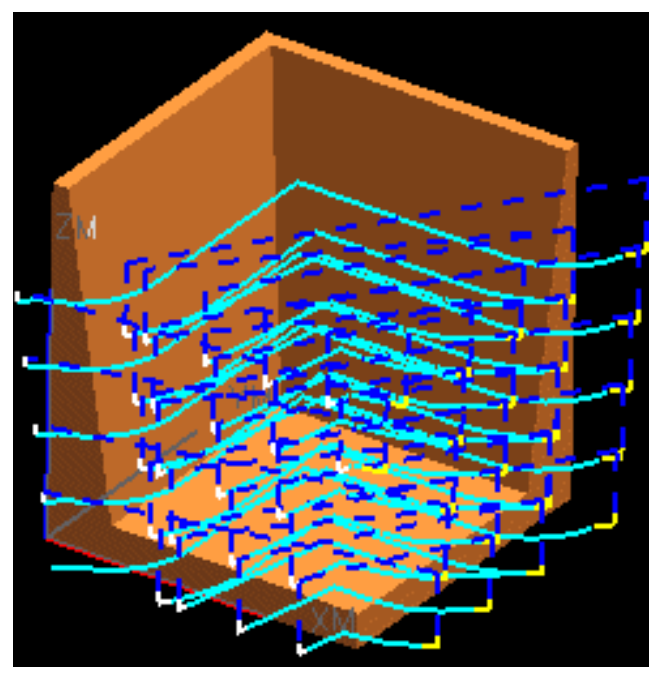

Figure 4. Tool path without reference tool

As shown in Figure 5, when the facing milling cutter with a diameter of 20 is roughly processed, the corner of workpiece has left more margin. At this time, the semifinishing or finishing sidewall contour is not reasonable. It is required to select D8 tool for another processing through taking D20 tool as reference. D8 tool should be adopted to process the areas that D20 tool is not involved in. The specific toolpaths and the complete results are shown in Figure 6.

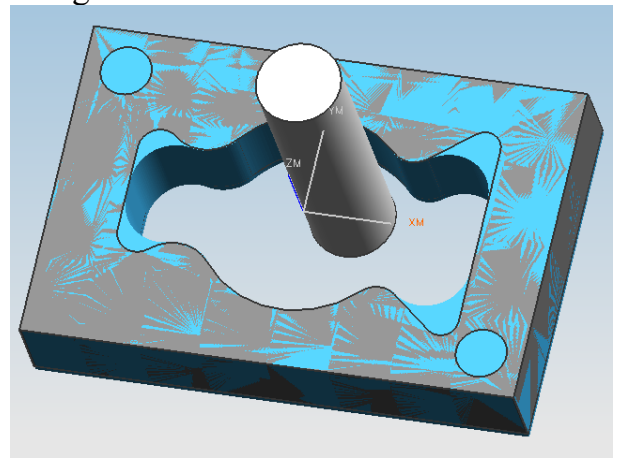

Figure 5. Facing milling cutter rough processing of D20

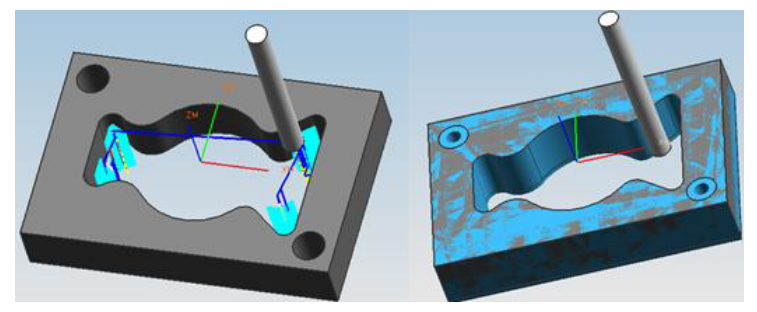

Figure 6. Tool paths and processing effects of D8 after using reference tool

\section{Gouging cutting of reference tools}

The gouging cutting is a cutter driving method in fixed axis milling surface profile. The gouging cutting method can be used in: high-speed machining; removing the excess materials in corner before finishing; removing the uncut materials left by larger ball facing mill. In gouging cutting, the reference tool can be employed for calculation. As shown in Figure 7, the diameter of roughing ball end mill is employed to specify the width 
of finishing cutting areas. The software calculates the double-cut points according to the specified "diameter of reference tool" . Then, these points are used to define the cutting areas of finishing process.

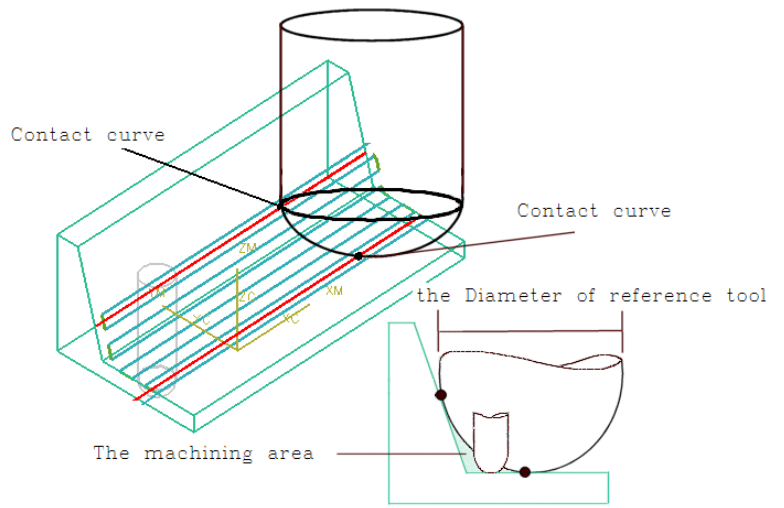

Figure 7. "Reference tools" are employed to conduct the gouging cutting

The part as shown in Figure 8 has been semi finished using ball end milling cutter with a diameter of 20 in previous process. In the example, a ball end mill with a diameter of 10 is used, which is suitable for the area that a ball end mill with a diameter of 20 is not suitable.

Figure 9 shows the tool path after machining using the ball end mill with a diameter of 10 and clear root driving using the ball end mill with a diameter of 20 as the reference tool. Figure 10 is the post processing effect diagram.

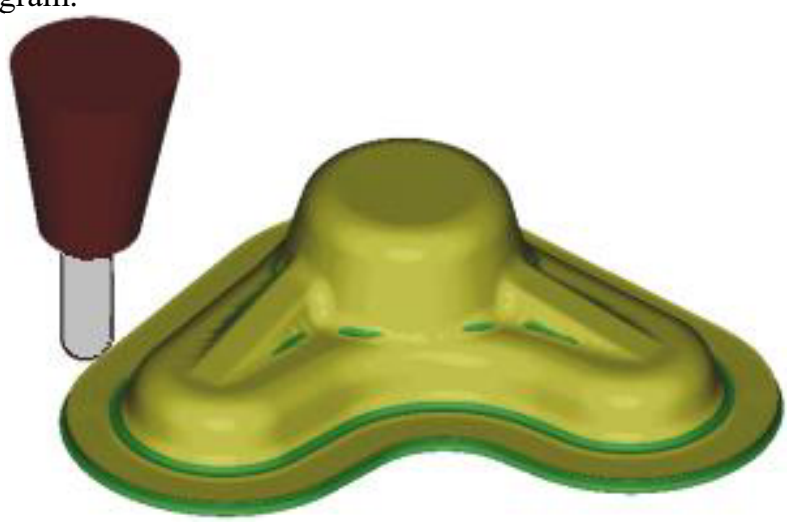

Figure 8. Part machined by the ball end mill with a diameter of 20

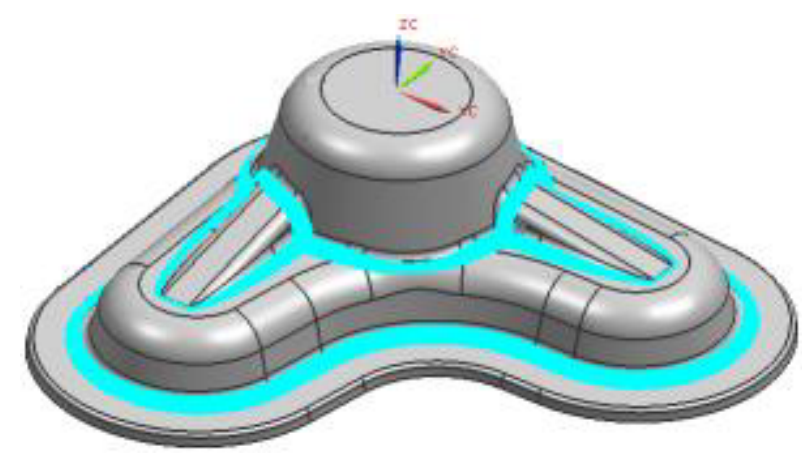

Figure 9. Tool path by the ball end mill with a diameter of 10 and the ball end mill with a diameter of 20 as the reference tool

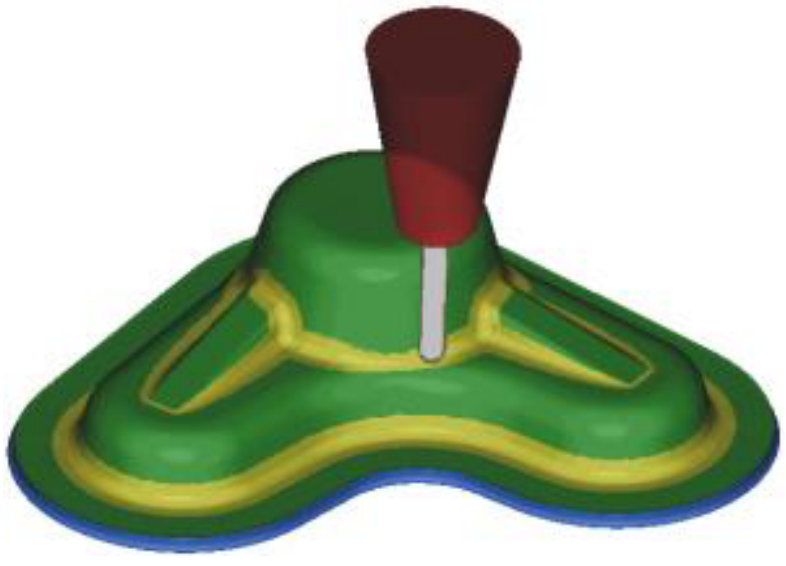

Figure 10. The post processing effect diagram

\section{Conclusions}

The applications of tools in NX CAM module can greatly facilitate the programmer. UG NX can support the establishment of custom magazine and the size as well as the materials of tools can be set. At the same time, the extremely detailed process data can be provided, such as the cutting depth, the stepping, the surface speed and the cutting feed rate, etc. The option of "using shank and holder" helps to avoid the collision between shank and workpiece. In the operation, it is required to choose the shortest tool as possible. The handle shape and the minimum clearance value can ensure the safe distance with geometry. The regions which can cause the collision will be excluded from the cutting area. Therefore, there is no toolpath collision when cutting materials. The "reference tool" method can better process the corner and gouge, reduce the tool idling and improve the efficiency.

\section{References}

1. Y.X. Liang, H.B. Zhao. MW Metal Cutting, 4(2001):8-10.

2. H.P. Zhang, Sh. Y. Meng, Y. Zh. Jia. MMAD, 23,6(2008):20-23.

3. UG NX HELP Documentation.

4. S.T. Chen. Tool Engineering, 45,7(2001):75-78. 